University of Nebraska - Lincoln

DigitalCommons@University of Nebraska - Lincoln

July 2001

\title{
Coercivity of titanium-substituted high-temperature permanent magnets
}

Jian Zhou

University of Nebraska - Lincoln

Ralph Skomski

University of Nebraska-Lincoln, rskomski2@unl.edu

David J. Sellmyer

University of Nebraska-Lincoln, dsellmyer@unl.edu

Follow this and additional works at: https://digitalcommons.unl.edu/physicssellmyer

Part of the Physics Commons

Zhou, Jian ; Skomski, Ralph; and Sellmyer, David J., "Coercivity of titanium-substituted high-temperature permanent magnets" (2001). David Sellmyer Publications. 54.

https://digitalcommons.unl.edu/physicssellmyer/54

This Article is brought to you for free and open access by the Research Papers in Physics and Astronomy at DigitalCommons@University of Nebraska - Lincoln. It has been accepted for inclusion in David Sellmyer Publications by an authorized administrator of DigitalCommons@University of Nebraska - Lincoln. 


\title{
Coercivity of Titanium-Substituted High-Temperature Permanent Magnets
}

\author{
Jian Zhou, Ralph Skomski, and David J. Sellmyer
}

\begin{abstract}
The temperature dependence of the coercivity of Sm-Co based magnets is investigated by magnetization measurements and model calculations. The $\mathrm{Zr}$-free titanium-substituted Sm-Co material exhibits a positive temperature coefficient $d H_{c} / d T$ of the coercivity (TCC) above room temperature, a reasonable hysteresis-loop shape, and an appreciable coercivity of $12.3 \mathrm{kOe}$ at $500{ }^{\circ} \mathrm{C}$ for the nominal composition $\operatorname{Sm}\left(\mathrm{Co}_{6.2} \mathrm{Cu}_{0.8} \mathrm{Ti}_{0.3}\right)$. The samples were produced by heat-treating the disordered $1: 5$ alloy commonly referred to as the $\mathrm{TbCu}_{7}$ (or $1: 7$ ) phase. X-ray diffraction analysis shows that, upon annealing at $1165{ }^{\circ} \mathrm{C}$, the starting material segregates into more-or-less stoichiometric $1: 5$ and 2:17 phases. The TCC is explained by taking into account that two-phase $\mathrm{Sm}-\mathrm{Co}$ magnets are of the pinning type, that is the coercivity is realized by capturing (or repelling) domain walls at $1: 5 / 2: 17$ phase boundaries. Starting from a planar-defect approach, the TCC is modeled as a function of the anisotropy constants of the involved phases. The present approach yields a fair agreement between theory and experiment, and explains the existence of a coercivity maximum in terms of the $\mathrm{Cu}$ concentration.
\end{abstract}

Index Terms-Domain wall pinning, high-temperature permanent magnets, $\mathrm{Sm}-\mathrm{Co}$ based permanent magnets, temperature dependence of coercivity.

\section{INTRODUCTION}

V ERY recently, permanent magnets with operating temperatures above $450{ }^{\circ} \mathrm{C}$ have become an area of worldwide scientific and industrial interest. $\mathrm{Sm}-\mathrm{Co}$ based magnets are the most promising candidates for the high-temperature applications because of their high Curie temperature and good magnetic properties. Conventional $\mathrm{Sm}_{2}(\mathrm{Co}, \mathrm{Fe}, \mathrm{Cu}, \mathrm{Zr})_{17}$ permanent magnets provide large coercivity and energy product at room temperature, but the negative temperature coefficient of coercivity (TCC) makes the 2:17 magnets unsuitable for the high temperature usage since the $H_{c}$ drops sharply to less than $5 \mathrm{kOe}$ at $450^{\circ} \mathrm{C}$. Efforts on improving the high temperature coercivities of the $2: 17$ magnets have been made by adjusting the composition and the heat treatment conditions and some good results have been obtained. In this context an abnormal temperature dependence of intrinsic coercivity has been found in the $\mathrm{Sm}_{2}(\mathrm{Co}, \mathrm{Fe}, \mathrm{Cu}, \mathrm{Zr})_{17}$ magnets by several groups [1]-[3]. Recently, we reported a $\mathrm{Sm}-\mathrm{Co}-\mathrm{Cu}-\mathrm{Ti}$ high-temperature permanent magnet with the positive temperature coefficient of

Manuscript received October 13, 2000.

This work was supported by the U.S. Air Force Office of Scientific Research and the Defense Advanced Projects Agency through the U.S. Army Research Office.

The authors are with Behlen Laboratory of Physics and Center for Materials Research and Analysis, University of Nebraska, Lincoln, NE 68588 (e-mail: \{jzhou; rskomski\}@unlserve.unl.edu; cmra@unl.edu).

Publisher Item Identifier S 0018-9464(01)06873-X coercivity [4]. In this paper we will present further improvements of the magnets performance of the material and give an explanation of the positive TCC behavior.

\section{SAMPLE PREPARATION}

A series of $\mathrm{Sm}\left(\mathrm{Co}_{7.05-x} \mathrm{Cu}_{x} \mathrm{Ti}_{0.25}\right)(x=0.4,0.5,0.6,0.65$, $0.7,0.8,0.9)$ samples were prepared by arc-melting the starting elements materials with purity of at least $99.9 \%$ under flowing argon. The samples were sealed in a quartz tube filled with argon and heat-treated in the following way: solutionized at $1165^{\circ} \mathrm{C}$ for $3 \mathrm{hrs}$, then cooled to $825^{\circ} \mathrm{C}$ and annealed for $8 \mathrm{hrs}$, followed by slowly cooling with a rate of $1{ }^{\circ} \mathrm{C} / \mathrm{min}$ down to $550^{\circ} \mathrm{C}$ for another 8 hrs. X-ray diffraction was used to determine the crystal structure. Hysteresis-loop measurements at room temperature and at elevated temperatures (up to $600^{\circ} \mathrm{C}$ ) were performed by VSM and SQUID.

\section{Structural AND Magnetic PROPERTIES}

The x-ray diffraction pattern show that the as-melted samples have the disordered $\mathrm{CaCu}_{5}(1: 5)$ structure which is commonly referred to as $\mathrm{TbCu}_{7}(1: 7)$ structure. After heat-treatment, the samples segregate into two phases: a nearly stoichiometric $1: 5$ grain-boundary phase and a main $\mathrm{Th}_{2} \mathrm{Zn}_{17}(2: 17)$ phase. Transmission electron microscopy shows that the microstructure is cellular and reminiscent of that of industrial 2:17 magnets. Details about the crystal structure and the microstructure can be found in our previous work [4]. The thermal-magnetic analysis confirmed the existence of this two-phase mixture.

Fig. 1 shows the typical hysteresis loops of a $\mathrm{SmCo}_{6.65} \mathrm{Cu}_{0.4} \mathrm{Ti}_{0.25}$ sample at different temperatures. The intrinsic coercivity of this sample increases as the temperature goes up, from $0.1 \mathrm{kOe}$ at the temperatures below $300{ }^{\circ} \mathrm{C}$ to a maximum value of $3.8 \mathrm{kOe}$ at $550{ }^{\circ} \mathrm{C}$. This coercivity change is reversible, i.e., the coercivity drops back to almost zero when the temperature goes back to room temperature after high temperature measurement. The magnets exhibit a positive temperature coefficient of the coercivity. Fig. 2 shows the temperature dependence of coercivity of five $\operatorname{Sm}\left(\mathrm{Co}_{7.05-x} \mathrm{Cu}_{x} \mathrm{Ti}_{0.25}\right)$ bulk samples with $x=0.4,0.5,0.6$, 0.65 and 0.8 . It can be seen that with increasing $\mathrm{Cu}$ content, the intrinsic coercivity of the samples increase and the temperature coefficient of coercivity decreases gradually to almost zero $(x=0.65)$. When $\mathrm{Cu}$ content is higher $(x>0.65)$, the TCC goes to negative value ( $x=0.7$ and 0.9 are not shown in the figure). A maximum value of $10.0 \mathrm{kOe}$ coercivity at $500{ }^{\circ} \mathrm{C}$ was obtained in the $\mathrm{Sm}\left(\mathrm{Co}_{6.25} \mathrm{Cu}_{0.8} \mathrm{Ti}_{0.25}\right)$ sample. To reach a higher $H_{c}$, we changed the composition of above sample 


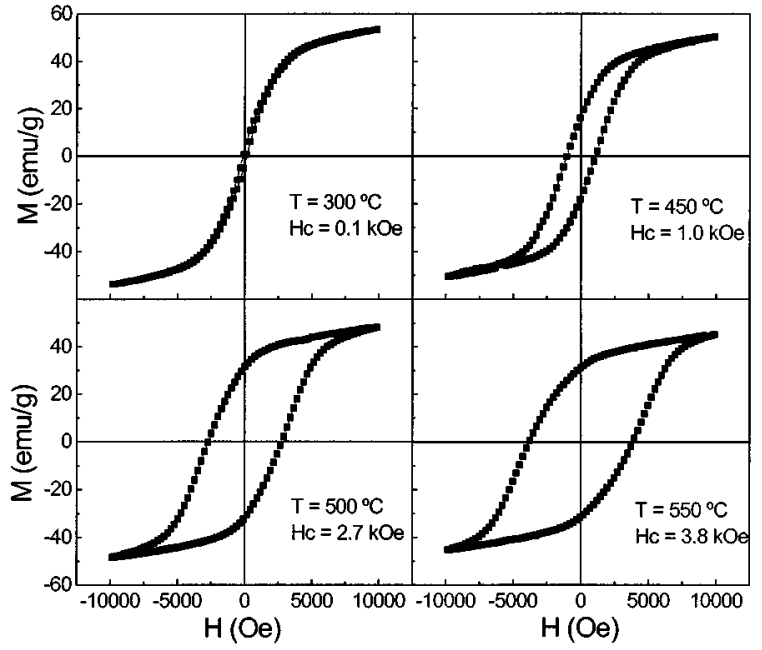

Fig. 1. Hysteresis loops of a $\mathrm{Sm}\left(\mathrm{Co}_{6.65} \mathrm{Cu}_{0.4} \mathrm{Ti}_{0.25}\right)$ sample at different temperatures.

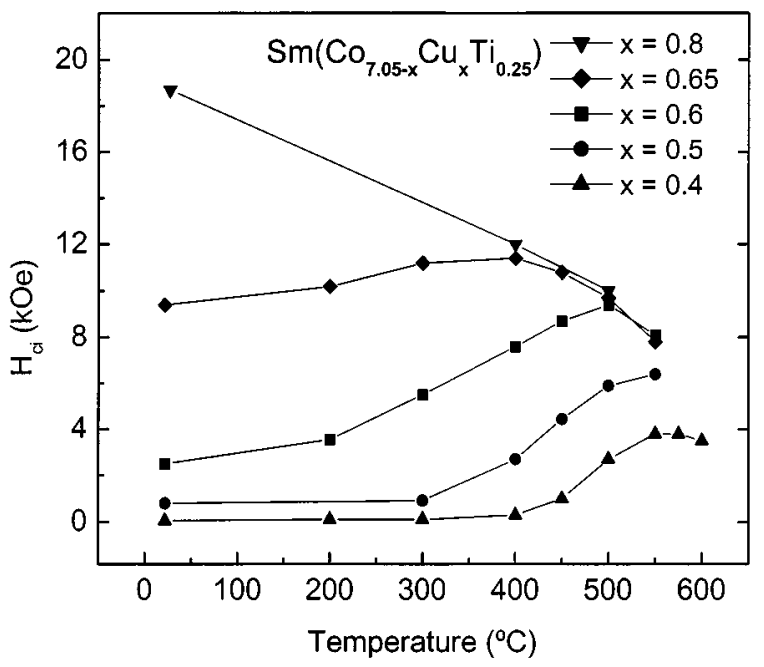

Fig. 2. Temperature dependence of intrinsic coercivities of $\mathrm{Sm}\left(\mathrm{Co}_{7.0 .5-x} \mathrm{Cu}_{x} \mathrm{Ti}_{0.25}\right)$ bulk samples with $x=0.4-0.8$.

slightly by adjusting the Ti amount to 0.3 . After same heat treatment condition, this $\operatorname{Sm}\left(\mathrm{Co}_{6.2} \mathrm{Cu}_{0.8} \mathrm{Ti}_{0.3}\right)$ sample showed a coercivity of $12.3 \mathrm{kOe}$ at $500^{\circ} \mathrm{C}$ (Fig. 3 shows a typical loop). Further investigations on the Ti content effect are under work.

\section{ORIGIN OF THE Positive TeMPeRATURe COEFFicIENT}

To explain the TCC we take into account that two-phase $\mathrm{Sm}-\mathrm{Co}$ magnets are of pinning type [5], that is the coercivity is realized by capturing (or repelling) domain walls at $1: 5 / 2: 17$ phase boundaries. There are two aspects: the interaction of a plane domain wall with the grain boundary [6] and the effect of the domain-wall curvature [7]. The pinning interaction of a plane wall is characterized by two effects. First, the domain-wall energy $g\left(x_{0}\right)$, where $x_{0}$ is the domain-wall position, acts as an attractive or repulsive potential which pins the wall. Second, the domain-wall fine structure of the wall changes on pinning. For example, if the grain-boundary region is soft-magnetic, then the domain-wall width increases.

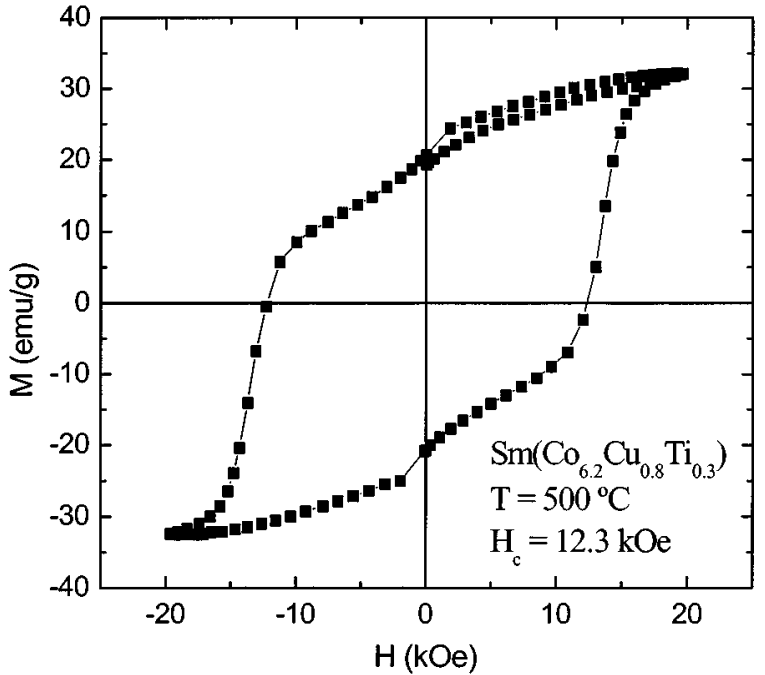

Fig. 3. Hysteresis loop of $\operatorname{Sm}\left(\mathrm{Co}_{6.2} \mathrm{Cu}_{0.8} \mathrm{Ti}_{0.3}\right)$ at $500{ }^{\circ} \mathrm{C}$.

A simple variational approach is to use a trial function for the magnetization $m=M_{z} / M_{s}$

$$
m\left(x, x_{0}, \lambda\right)=\tanh \left(\frac{x-x_{0}}{\lambda}\right)
$$

where $\lambda$ is a wall-width parameter and $x_{0}$ is the position of the wall. After some calculation, we obtain the following expression for the pinning energy

$$
\begin{aligned}
\operatorname{Ep}\left(\lambda, x_{0}\right)= & \eta(\lambda) \cdot \lambda \cdot\left(\tanh \left(\frac{b-x_{0}}{\lambda}\right)+\tanh \frac{x_{0}}{\lambda}\right) \\
& -\mu_{0} \cdot H \cdot\left(M_{s}-M_{h}\right) \cdot \lambda \\
& \cdot \ln \left(\cosh \left(\frac{b-x_{0}}{\lambda}\right) / \cosh \frac{x_{0}}{\lambda}\right)
\end{aligned}
$$

where

$h$ and $s$ are the indices which refer to the main and boundary phases, respectively,

$b \quad$ is the thickness of the boundary phase, and

$\eta(\lambda)=\left(A_{s}-A_{h}\right) / \lambda^{2}+K_{s}-K_{h}$.

Minimizing the total energy with respect to $x_{o}$ and $\lambda$ yields two coupled nonlinear and field-dependent equations, and the coercivity is determined by the condition $\partial H / \partial x_{0}=0$. The solution of this problem goes beyond the scope of this work, but it can be shown that the coercivity can be approximated by the well-known equation

$$
H_{c}=H_{0} \cdot\left(\frac{\pi \cdot b}{3 \sqrt{3} \cdot \delta} \cdot \frac{|\Delta K|}{K_{h}}\right)
$$

where $H_{\circ}$ is the anisotropy field of the main phase. Essentially, the corrections to this equation, which is exact for thin boundaries $b \ll \delta$, amount to the replacement of the factor $\pi /(3 \sqrt{ } 3)$ by a weakly exchange and boundary-thickness dependent function.

The domain-wall curvature, which reflects the geometry of the cellullar structure of the magnet, has been outlined in [7] and is automatically contained in full-scale simulations [8]. Plane walls in complicated structures may exhibit a very low coercivity, because $K_{1}(\boldsymbol{r})$ is largely averaged inside the wall, 


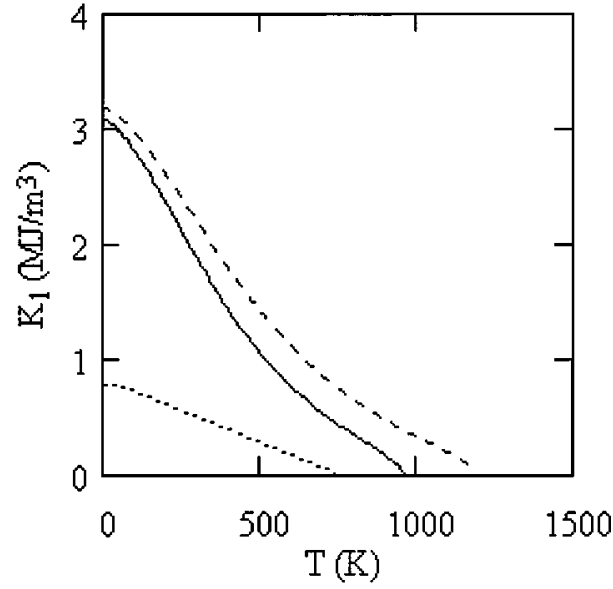

Fig. 4. Schematic temperature dependencies of anisotropy for a main phase (dashed line) and grain-boundary phases [9] having moderate $\mathrm{Cu}$ content (solid line) and high $\mathrm{Cu}$ content (dotted line).

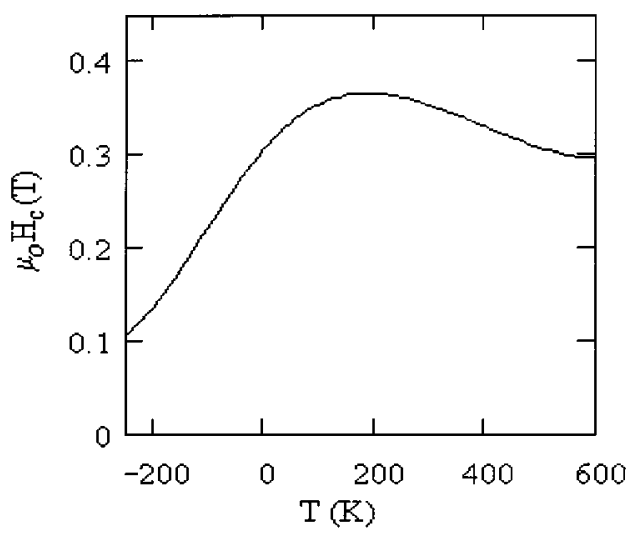

Fig. 5. Model calculation of the temperature dependence of the pinning coercivity.

so that some wall curvature is necessary to locally plane walls and to realize the coercivity (3). However, very high curvatures indicate magnetic softness and reduce the coercivity by suppressing $H_{o}$. Note that the plane-wall pinning and curvature effects are the main contributions to the pinning coercivity; magnetic viscosity is a small coercivity-reducing correction to these two effects [9].

Equation (3) shows that the pinning coercivity is essentially proportional to the anisotropy difference $\Delta K=\left|K_{h}-K_{s}\right|$ between the two involved phases. Fig. 4 shows typical temperature dependencies for a main phase (dashed line) and a grain-boundary phase (solid line), whereas the corresponding temperature dependence of the coercivity is shown in Fig. 5. It is important to note that $K_{1}(T)$ exhibits a pronounced dependence on the chemical composition. In particular, $\mathrm{Cu}$ strongly reduces the anisotropy of the 1:5 grain-boundary phase [3]. This is the origin of the composition dependence of the curves shown in Fig. 2: moderate amounts of $\mathrm{Cu}$ yield $K_{1}(T)$ dependencies similar to the solid line in Fig. 4 and give rise to a coercivity maximum, whereas a further increase of the $\mathrm{Cu}$ content suppresses the anisotropy at all temperatures (dotted curve in Fig. 4) and the coercivity becomes a monotonously decreasing function of the temperature. (Note that the low-temperature anisotropy of $\mathrm{Cu}$-free $\mathrm{SmCo}_{5}$ is much higher than that of $\mathrm{Sm}_{2} \mathrm{Co}_{17}$.) For intermediate $\mathrm{Cu}$ contents it follows from Fig. 4 that there are also temperatures at which $\Delta K=0$. In this case, (3) predicts $H_{c}=0$, but in reality there are chemical concentration fluctuations [10], so that the material is never truly homogeneous.

\section{CONCLUSIONS}

A Sm( $\left(\mathrm{Co}_{7.05-x} \mathrm{Cu}_{x} \mathrm{Ti}_{0.25}\right)(x=0.4-0.9)$ series of bulk samples were investigated and a positive temperature coefficient of coercivity was found in low $\mathrm{Cu}$ content samples $(x \leq 0.65)$. When the $\mathrm{Cu}$ content is high $(x>0.65)$, the TCC changes to negative value. A $\mathrm{Sm}\left(\mathrm{Co}_{6.4} \mathrm{Cu}_{0.65} \mathrm{Ti}_{0.25}\right)$ sample with positive TCC reaches the maximum $H_{c}$ of $9.7 \mathrm{kOe}$ at $500{ }^{\circ} \mathrm{C}$, while a $\mathrm{Sm}\left(\mathrm{Co}_{6.2} \mathrm{Cu}_{0.8} \mathrm{Ti}_{0.3}\right)$ sample with negative TCC gives an $H_{c}$ of $12.3 \mathrm{kOe}$ at $500{ }^{\circ} \mathrm{C}$. This behavior is explained in terms of domain wall pinning mechanism in a two-phase magnet.

\section{REFERENCES}

[1] J. F. Liu, T. Chui, D. Dimitrov, and G. C. Hadjipanayis, "Abnormal temperature dependence of intrinsic coercivity in $\mathrm{Sm}(\mathrm{Co}, \mathrm{Fe}, \mathrm{Cu}, \mathrm{Zr})_{z}$ powder materials," Appl. Phys. Lett., vol. 73, pp. 3007-3009, Nov. 1998.

[2] S. Liu, J. Yang, G. Doyle, G. Potts, and G. E. Kuhl, "Abnormal temperature dependence of intrinsic coercivity in sintered Sm-Co-based permanent magnets," J. Appl. Phys., vol. 87, pp. 6728-6730, May 2000.

[3] D. Goll, I. Kleinschroth, W. Sigle, and H. Kronmüller, "Melt-spun precipitation-hardened $\mathrm{Sm}_{2}(\mathrm{Co}, \mathrm{Cu}, \mathrm{Fe}, \mathrm{Zr})_{17}$ magnets with abnormal temperature dependence of coercivity," Appl. Phys. Lett., vol. 76, pp. 1054-1056, Feb. 2000

[4] J. Zhou, R. Skomski, C. Chen, G. C. Hadjipanayis, and D. J. Sellmyer, "Sm-Co-Cu-Ti high-temperature permanent magnets," Appl. Phys. Lett., vol. 77, pp. 1514-1516, Sept. 2000.

[5] J. Fidler, "Coercivity of precipitation hardened cobalt rare earth $17: 2$ permanent magnets," J. Magn. Magn. Mater, vol. 30, pp. 58-70, 1982.

[6] R. Becker and W. Döring, Ferromagnetismus. Berlin: Springer, 1939.

[7] R. Skomski, "Finite-temperature behavior of anisotropic two-sublattice magnets," J. Appl. Phys., vol. 83, pp. 6724-6726, June 1998.

[8] B. Streibl, J. Fidler, and T. Schrefl, "Domain wall pinning in high temperature $\mathrm{SM}(\mathrm{Co}, \mathrm{Fe}, \mathrm{Cu}, \mathrm{Zr})_{7-8}$ magnets," J. Appl. Phys., vol. 87, pp. 4765-4767, May 2000.

[9] R. Skomski and J. M. D. Coey, Permanent Magnetism. Bristol: Institute of Physics, 1999.

[10] G. C. Hadjipanayis, W. Tang, Y. Zhang, S. T. Chui, J. F. Liu, C. Chen, and H. Kronmüller, IEEE Trans. Magn., to be published. 